\title{
Uma proposta de arcabouço teórico para análise do comportamento dos investimentos diretos estrangeiros em economias emergentes
}

\author{
A proposed theoretical framework for the \\ determinants factors for outward investments from \\ emerging countries
}

\section{Paulo Roberto do Amaral Ferreira ${ }^{1}$ Luís Antônio da Rocha Dib²}

\begin{abstract}
Resumo
O objetivo deste ensaio teórico foi identificar determinantes dos investimentos diretos outward de firmas com sede em países considerados emergentes. Foi feita análise crítica da base de dados da UNCTAD e revisão da teoria do Investment Development Path (Teoria IDP), proporcionando a integração dos resultados de estudos empíricos relacionados a investimentos diretos com a literatura mais pertinente. A conclusão da pesquisa permitiu a sugestão de um arcabouço teórico contendo determinantes que podem empurrar ou puxar investimentos outward a partir de economias emergentes. Tal arcabouço visa ampliar a contribuição da Teoria IDP, sugerindo determinantes complementares ao PIB per capita. Com relação ao estado da prática, o arcabouço pode servir de orientação para estratégias de internacionalização de firmas de economias emergentes, assim como para o direcionamento de políticas governamentais de tais países.
\end{abstract}

Palavras-chaves: Investimento outward. Economias emergentes. IDP theory. Investimento direto estrangeiro.

Doutorado em andamento em Administração, Universidade Federal do Rio de Janeiro, UFRJ. Mestre em Administração Universidade Federal do Rio de Janeiro, UFRJ. Docente no Instituto Federal do Rio de Janeiro (IFRJ) - Brasil - pauloraferreira@hotmail.com

2 Doutorado em Administração. Instituto COPPEAD de Administração/UFRJ. Professor-chefe da área de Marketing e Negócios Internacionais do Instituto COPPEAD (UFRJ) - Brasil - dib@ coppead.ufrj.br 


\section{Abstract}

The purpose of the study presented here in the form of a theoretical essay was to identify determinants factors for outward foreign direct investments by companies headquartered in countries rated as emerging economies. A critical analysis was conducted on the UNCTAD database and a review of the Investment Development Path(IDP) Theory, fostering the integration of the findings of empirical studies related to direct investments in the most pertinent literature. The conclusion reached by this research underpins the suggestion of a theoretical framework with key factors that might push or pull outward investments from emerging countries. This framework is intended to boost the contributions of IDP Theory, suggesting determinants factors that are supplementary to the per capita GDP. With regard to the state of the art, this framework may provide guidelines for the internationalization strategies of firms in the emerging countries, as well as for steering government policies in these countries.

Keywords: Outward investment. Emerging countries. IDP Theory. Foreign direct investment.

\section{Introdução}

Este ensaio teórico concentrou sua análise na internacionalização de empresas por meio de investimentos diretos no exterior (IDE). Tais investimentos visam ao longo prazo e são realizados para a construção de subsidiárias, aquisição de empresas, construção de escritórios de venda, entre outros (Johanson \& Vahlne, 1977; 2013; Dunning, 1980; 1988).

De acordo com Narula e Dunning (1996; 2010), um modo de classificar o investimento direto estrangeiro seria em: (1) investimento direto do tipo inward - IFDI (fluxo de investimento que parte do mercado internacional para o mercado doméstico), e (2) investimento direto do tipo outward - OFDI (fluxo de investimento que parte do mercado doméstico para o mercado internacional). Na pesquisa aqui apresentada, foram analisados fenômenos relacionados com "investimentos outward", uma vez que se trata de um tipo de investimento ainda incipiente em economias emergentes (UNCTAD, 2013), com diversas oportunidades de estudo e aprofundamento de seus determinantes. 
Grande parte dos estudos sobre investimentos diretos estrangeiros (IDE) foi realizada por pesquisadores que deram enfoque em aspectos macroeconômicos e microeconômicos de "economias desenvolvidas", com o intuito de compreender seus determinantes (Chow, 2012; Goldstein, Gammeltoft \& Pradhan, 2010; Goldstein \& Pusterla, 2010; Herzer, 2010; Ju, Kim, Bae \& Know 2012; Quer, Claver \& Rienda, 2011; Rasiah, Gammeltoft \& Jiang, 2010). Porém, ultimamente, o fluxo de investimentos diretos das economias emergentes vem crescendo continuamente. De acordo com a base de dados estatísticos da UNCTAD (2013), a proporção da emissão de investimentos diretos no exterior entre economias desenvolvidas e economias emergentes era 1:20 em 1990 e passou para 1:3 em 2013, chamando atenção dos pesquisadores para os determinantes deste comportamento no novo cenário dos negócios internacionais.

Pode-se destacar, ainda, o fato de que existem inúmeros benefícios de médio e longo prazos oriundos dos IDE outward para os países investidores e suas empresas. Dentre os benefícios, pode-se destacar o aumento de competitividade das firmas locais, transferência de conhecimento, transferência de tecnologia, network com fornecedores e operadores logísticos a nível mundial, acesso à mão de obra qualificada, acesso à mão de obra barata, acesso a mercados financeiros globais, entre outros (Apergis, 2009; Baer \& Sirohi, 2013; Chen, Hsu \& Wang, 2012; Chow, 2012; Davies, 2013; Globerman, 2012; Herzer, 2010; Ketkar, 2014; Kahanidra, 2013; Lee, 2010; Quer et al., 2011; Qiang, 2013; Radlo \& Sass, 2012; Rasiah et al., 2010).

Portanto, a partir da relevância dos investimentos outward para os países e suas firmas, e da escassez de respostas e estudos relacionados aos obstáculos enfrentados pelas economias emergentes na maximização desses investimentos, surgiu a motivação para o estudo aqui apresentado, cujo objetivo foi mapear determinantes que influenciam estratégias de investimentos outward no caso específico de empresas com sede em economias emergentes. Para atender a esse objetivo, foram definidas as seguintes questões de auxiliares para pesquisa: 
- Qual o comportamento dos investimentos inward e outward nas economias emergentes?

- Como explicar o comportamento dos investimentos diretos em economias emergentes?

- Quais são os determinantes dos investimentos outward em economias emergentes?

- Quais são as motivações dos investimentos outward em economias emergentes?

- Quais são as vantagens competitivas que as firmas de economias emergentes necessitam adquirir para que possam executar, de forma sustentável, uma estratégia de investimento outward?

Para responder tais questões, optou-se por uma pesquisa qualitativa exploratória, por meio da revisão e integração dos resultados de estudos empíricos anteriores e comparação de seus resultados com a literatura, por meio de pesquisa bibliográfica e documental, com objetivo de identificar relações de determinantes com investimentos outward. Além disso, utilizou-se a base de dados estatísticos da UNCTAD com o objetivo de avaliar longitudinalmente o estoque de IDEs em economias emergentes e desenvolvidas no período de 1990 a 2013. Por fim, utilizou-se também a teoria do IDP (Investment Development Path), proposta por Narula e Dunning (1996), para tentar explicar a dinâmica do comportamento dos IDEs em economias emergentes.

Essa análise não só permitiu relacionar diversos determinantes com crescimento e queda de investimentos inward e outward, como também avaliar se existe alguma relação longitudinal entre esses dois investimentos. Adicionalmente, tais resultados possibilitaram contribuir com a Investment Development Path (IDP Theory), proposta por Narula e Dunning (1996; 2010), com a apresentação de determinantes alternativos aos apresentados pela Teoria IDP e que também influenciam no comportamento dos IDEs. Tais determinantes são compilados em um arcabouço teórico que complementa o modelo apresentado pela Teoria IDP. 


\section{Contexto do estudo}

Para entender o comportamento dos investimentos inward e outward em economias emergentes, buscou-se descrever a situação em países deste tipo, como Brasil, China, Rússia, Índia e África do Sul, e também em economias desenvolvidas, como Estados Unidos, Reino Unido, Alemanha, França e Japão (para efeito de comparação). Utilizouse como parâmetro o "estoque" de investimentos diretos estrangeiros, e não o "fluxo" de investimentos, pois houve o interesse de compreender o comportamento longitudinal dos IDE, fato visualizado pelas oscilações históricas no estoque. O objetivo deste tópico foi ressaltar as diferenças no comportamento dos investimentos inward e outward: (a) entre economias emergentes, (b) entre economias desenvolvidas, e (c) entre economias desenvolvidas e em desenvolvimento.

Todos os dados apresentados foram coletados da base de dados estatísticos da UNCTAD (www.unctad.org), no período de 1990 a 2013. Optou-se pela UNCTAD pelo fato de ser uma das principais bases de dados sobre investimentos diretos no mundo. Optou-se pela coleta de dados a partir de 1990, por ser um divisor de águas em relação ao fenômeno da globalização contemporânea (Dib, Rocha \& Silva, 2010).

A Tabela 1 mostra o estoque de investimento inward e outward em algumas economias emergentes e desenvolvidas no período de 2010 a 2013. Representando as economias emergentes, optou-se pelos países que compõem o grupo dos BRIC (Brasil, Rússia, Índia, China e África do Sul), que apresentam participação, cada vez maior, no fluxo de investimentos diretos mundiais (UNCTAD, 2013). Pelo lado das economias desenvolvidas (concentrados na América do Norte e na Europa), deu-se destaque para os Estados Unidos, Reino Unido, Alemanha, França e Japão, que estão entre os maiores investidores diretos no mundo (UNCTAD, 2013).

Nota-se que a China (somando-se os dados de Hong Kong, Macau e Taiwan) se destaca tanto na captação de investimentos como na realização de investimentos no exterior, ficando atrás somente dos 
Estados Unidos em valores absolutos. Uma pequena parcela do total de investimentos inward e outward no mundo é direcionada para países com economias em transição (que estão mudando de centralmente planificada para o mercado livre), como Albânia, Armênia, Azerbaijão, Sérvia, entre outros. As economias em transição não foram inclusas na Tabela 1 por representarem percentuais pouco representativos do estoque de investimentos inward e outward no mundo.

Tabela 1 - Estoque de investimentos inward e outward por economias emergentes e desenvolvidas em milhões de dólares

\begin{tabular}{|c|c|c|c|c|c|c|c|c|c|}
\hline \multicolumn{5}{|c|}{ ESTOQUE DE INVESTIMENTO INWARD (USD MILHŌES) } & \multicolumn{5}{|c|}{ ESTOQUE DE INVESTIMENTO OUTWARD (USD MILHÕES) } \\
\hline & 2010 & 2011 & 2012 & 2013 & & 2010 & 2011 & 2012 & 2013 \\
\hline PED & & & & & PED & & & & \\
\hline China & 1827 & 1966 & 2267 & 2485 & China & 1548 & 1768 & 2019 & 2213 \\
\hline Brasil & 682 & 696 & 745 & 724 & Brasil & 191 & 206 & 271 & 293 \\
\hline Rússia & 490 & 454 & 496 & 575 & Rússia & 366 & 362 & 406 & 501 \\
\hline Îndia & 205 & 206 & 224 & 226 & İndia & 97 & 109 & 118 & 120 \\
\hline África do Sul & 179 & 159 & 163 & 140 & África do Sul & 83 & 97 & 112 & 96 \\
\hline PD & & & & & PD & & & & \\
\hline Estados Unidos & 3422 & 3510 & 3923 & 4935 & Estados Unidos & 4809 & 4514 & 5249 & 6349 \\
\hline Reino Unido & 1136 & 1184 & 1482 & 1605 & Reino Unido & 1636 & 1696 & 1738 & 1885 \\
\hline França & 990 & 973 & 1029 & 1081 & França & 1516 & 1503 & 1569 & 1637 \\
\hline Alemanha & 716 & 737 & 788 & 851 & Alemanha & 1463 & 1494 & 1579 & 1710 \\
\hline Japão & 214 & 226 & 205 & 171 & Japåo & 831 & 963 & 1055 & 992 \\
\hline Total PED & 6597 & 6942 & 7945 & 8483 & Total PED & 3484 & 3928 & 4459 & 4993 \\
\hline Total PD & 13040 & 13425 & 14536 & 16053 & Total PD & 17241 & 17107 & 18672 & 20764 \\
\hline Total Mundo & 20370 & 21117 & 23304 & 25464 & Total Mundo & 21130 & 21441 & 23592 & 26312 \\
\hline \multicolumn{10}{|c|}{$\begin{array}{ll}\text { "China engloba Hong Kong, Macau e Taiwan } & \text { Fonte: UNCTAD } \\
\text { "PED = Paises em desenvolvimento } & \\
\text { •PD }=\text { Paises desenvolvidos } & \end{array}$} \\
\hline
\end{tabular}

Fonte: UNCTAD (2014).

A Figura 1 mostra o comportamento longitudinal dos investimentos inward e outward, entre 1990 e 2013, das economias desenvolvidas e em desenvolvimento. Enquanto no gráfico das economias emergentes o investimento inward apresenta maior montante do que os investimentos outward, no gráfico das economias desenvolvidas o comportamento é inverso. Observa-se também que, em ambos os gráficos, a correlação entre os investimentos parece diminuir ao longo do tempo, fazendo com que as curvas de investimento inward e outward ficassem mais separadas do que juntas no final do período avaliado. 
Figura 1 - Evolução dos investimentos inward e outward em economias emergentes e desenvolvidos, no período de 1990 a 2013
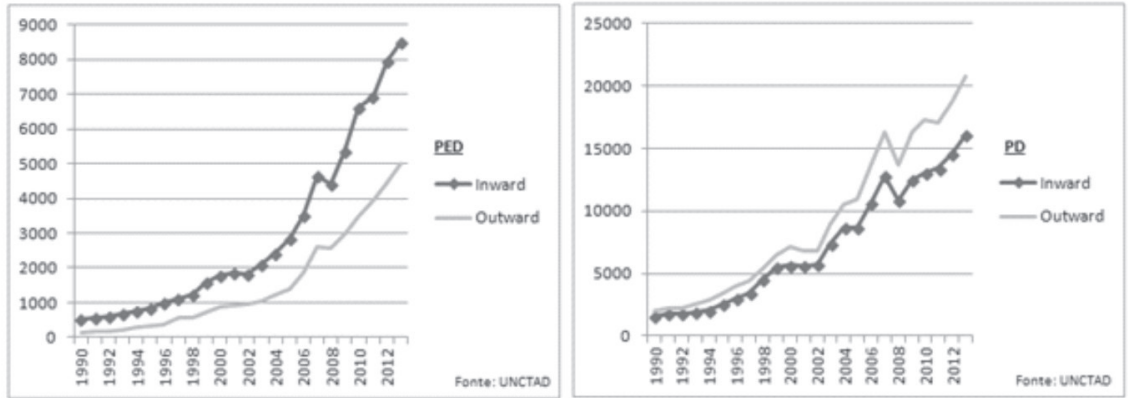

Fonte: UNCTAD (2014).

Nas Figuras 2 e 3, é possível ver exemplos específicos do comportamento dos investimentos inward e outward em economias emergentes e desenvolvidas. Acompanhando o padrão mostrado pelas economias emergentes na Figura 1, tanto a China como o Brasil (Figura 2) apresentam montantes longitudinais de investimentos inward maiores do que os investimentos outward de 1990 a 2013. Cabe ressaltar dois aspectos: (1) apesar de os gráficos apresentarem similaridades, os montantes de investimentos na China são consideravelmente maiores do que no Brasil. Além disso, (2) a China também apresenta maior correlação entre os investimentos, fato que pode ser visualizado pela maior proximidade entre suas curvas ao longo do período avaliado. Portanto, apesar de as economias emergentes apresentarem um comportamento padrão na evolução dos investimentos inward e outward, percebe-se a presença de características que diferem esses países, como volume de investimento e correlação entre as curvas. 
Figura 2 - Evolução dos investimentos inward e outward na China e no Brasil, no período de 1990 a 2013
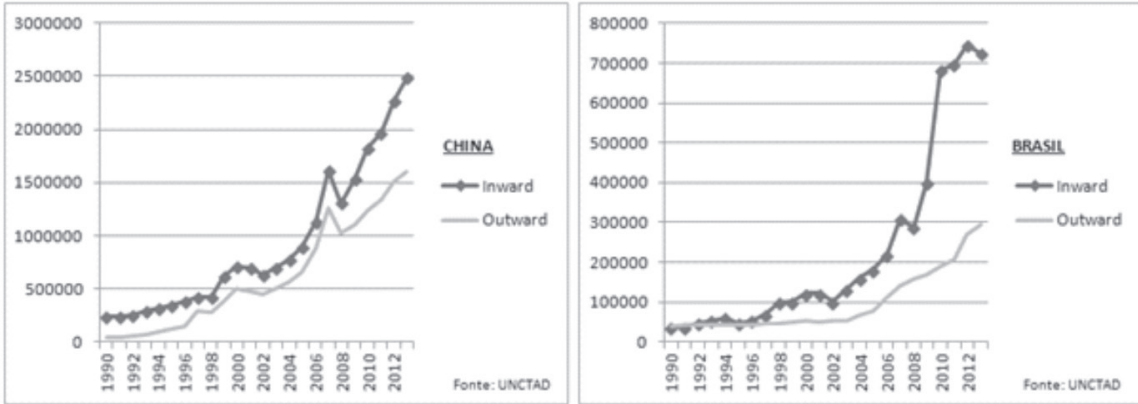

Fonte: UNCTAD (2014).

A Figura 3 apresenta uma comparação entre dois países pertencentes ao grupo das economias desenvolvidas. Tanto o gráfico dos Estados Unidos como o gráfico do Reino Unido apresentam similaridades e diferenças, conforme já discutido na Figura 2. No que diz respeito às similaridades, destaca-se o maior montante de investimento outward em relação ao investimento inward (comportamento oposto ao visto nos gráficos das economias emergentes) e a tendência positiva de ambos os investimentos no período avaliado (comportamento similar ao visto nos gráficos das economias emergentes). Por outro lado, destaca-se as diferenças entre os montantes dos investimentos nos Estados Unidos e no Reino Unido, além da correlação entre as curvas de investimento inward e outward, com maior correlação (proximidade) no gráfico norteamericano, quando comparado com o gráfico do Reino Unido. 
Figura 3 - Evolução dos investimentos inward e outward nos Estados Unidos e no Reino Unido, no período de 1990 a 2013
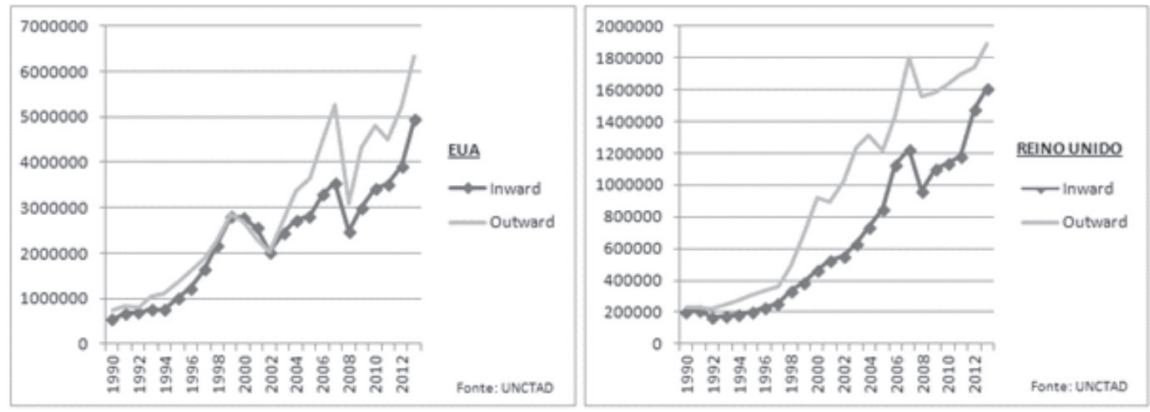

Fonte: UNCTAD (2014).

Observando as figuras e tabelas apresentadas anteriormente, fica evidente um comportamento padrão entre os investimentos inward e outward em economias emergentes e economiasdesenvolvidas. Percebese que o montante de investimentos inward foi maior do que montante de investimentos outward, no período de 1990 a 2013, nas economias emergentes. Já nas economias desenvolvidas, o comportamento padrão observado é o oposto do observado nas economias emergentes.

Uma vez analisado longitudinalmente os estoques de IDE inward e outward em economias desenvolvidas e em desenvolvimento, podese dizer algo a respeito da diferença entre o estoque de IDE outward e inward em economias emergentes e em economias desenvolvidas, representado pela sigla $\mathrm{NOI}(\mathrm{NOI}=$ estoque de IDE outward - estoque de IDE inward), sigla proposta por Narula e Dunning (1996). Concluise que o NOl é diferente em economias desenvolvidas e emergentes. Enquanto em economias desenvolvidas o NOl é positivo (estoque de IDE outward> estoque de IDE inward), nas economias emergentes o NOI é negativo (estoque de IDE outward< estoque de IDE inward). 


\section{Revisão da literatura}

\subsection{A Teoria IDP}

Uma vez descrito o padrão observado de comportamento dos investimentos inward e outward em economias desenvolvidas e em desenvolvimento, a próxima questão trata de "como" explicar o comportamento dos IDEs em economias emergentes. Para isto, recorreu-se à Teoria do Investment Development Path (Teoria IDP), proposta inicialmente por Dunning em 1981 e atualizada por Narula e Dunning em 1996 e 2010 (Narula \& Dunning, 1996; 2010).

A Teoria IDP analisa como padrões de IDEs respondem a mudanças nas vantagens propostas pelo Paradigma Eclético (vantagens OLI), tais como vantagens de propriedade das firmas domésticas e de firmas multinacionais (MNE), e vantagens de localização dos países receptores de investimentos diretos. De acordo com Narula e Dunning (1996; 2010), essa interação dinâmica entre vantagens de propriedade e vantagens locacionais influencia no desenvolvimento do país hospedeiro (mensurado pelo PIB per capita) e pode ser categorizada em cinco estágios, os quais podem ser aplicados aos países.

- Primeiro estágio: reflete a situação dos países menos desenvolvidos, onde os volumes de investimentos inward e outward são muito pequenos. Esses países carecem de vantagens de propriedade e de localização, que pode ser justificada por uma combinação de mercado doméstico limitado, carência de infraestrutura, mão de obra pouco qualificada e políticas governamentais inapropriadas.

- Segundo estágio: o volume de investimentos inward cresce significantemente graças ao desenvolvimento de algumas vantagens específicas de localização, que aumentam a atratividade do país em relação às multinacionais. Entretanto, o volume de investimentos outward permanece muito limitado pelo fato das vantagens de propriedade das firmas domésticas ainda permanecerem pouco competitivas, dando origem a um investimento líquido (NOI = outward-inward) muito abaixo de 1. 
- Terceiro estágio: o volume de investimentos outward aumenta, uma vez que as firmas domésticas tornam-se mais competitivas em relação às firmas multinacionais. Nesse estágio, o fluxo de investimento outward pode superar o fluxo de investimento inward, porém, o estoque de investimento inward permanece alto, fazendo com que o NOI permaneça negativo.

- Quarto estágio: o NOI torna-se positivo após crescimento contínuo dos investimentos outward resultante do desenvolvimento de vantagens de propriedade das firmas locais. O estoque de investimento outward é igual ou maior ao estoque de investimento inward. À medida que as firmas domésticas internacionalizam, elas se tornam multinacionais e adquirem mais vantagens competitivas.

- Quinto estágio: é o nível em que se encontram as economias desenvolvidas. $\mathrm{O} \mathrm{NOI}$ esperado gira em torno de zero, de forma instável, ora com resultados positivos, ora com resultados negativos. Segundo Narula e Dunning (1996; 2010), é importante destacar dois pontos: (1) todos os cinco estágios são indicativos; (2) o progresso dentro dos estágios e entre os estágios não ocorre de forma automática. Países podem tanto regredir como progredir nos cinco estágios propostos.

Aabordagem proposta pela Teoria do Caminho do Desenvolvimento do Investimento tem como modelo uma representação gráfica padrão dos investimentos diretos estrangeiros (IDEs), conforme mostrado na Figura 4. 
Figura 4 - Representação gráfica do comportamento do OFDI, do IFDI e do NOI nos cinco estágios propostos pela Teoria do Caminho do Desenvolvimento dos investimentos (IDP Theory)

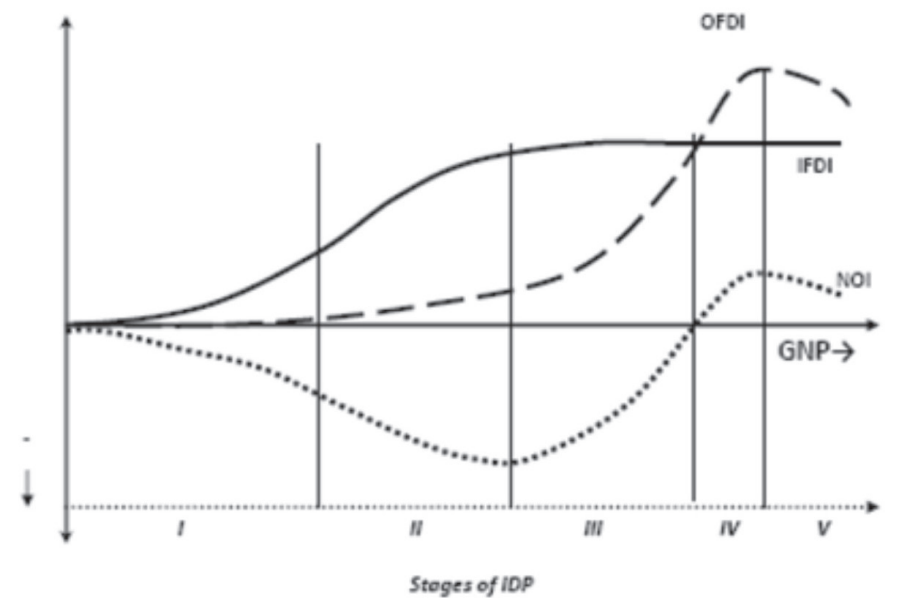

Fonte: Narula e Dunning (1996).

Segundo Narula e Dunning (2010), é importante compreender que o IDP de países individuais é diferente. Cada país segue seu próprio IDP, que reflete características determinadas por fatores exógenos (macroambiente e mesoambiente), tais como tamanho, população, localização geográfica, propriedade de recursos naturais, fatores econômicos e políticos, entre outros. Portanto, a comparação entre países deve ser feita com bastante parcimônia.

Narula e Dunning $(1996 ; 2010)$ deram um passo teórico importante na busca pela explicação do comportamento dos IDEs nas economias desenvolvidas e em desenvolvimento. No entanto, condicionar tal comportamento às variáveis PIB per capita, vantagens de propriedades e vantagens de localização é uma limitação da Teoria IDP, pois diversas outras variáveis poderiam influenciar o comportamentos dos IDEs. Embora Narula e Dunning (2010) reconheçam a necessidade da inclusão de mais variáveis na Teoria IDP, os autores não explicam "como" fazê-lo, deixando um gap para futuras pesquisas. 
Assim, pode-se dizer que a Teoria IDP complementa a proposição feita anteriormente de que o estoque de IDE inward é maior do que o estoque de IDE outward em economias emergentes, caracterizando um NOI negativo. Segundo a Teoria IDP, ao longo do tempo, o NOI passará de negativo a positivo, caracterizando uma evolução dos investimentos outwards em economias emergentes. A evolução do NOI de negativo a positivo se dará em cinco etapas. Em cada uma das cinco etapas, a evolução do NOI tem relação direta com o desenvolvimento econômico (PIB per capita), resultante da interação dinâmica entre vantagens de localização da economia emergente hospedeira e vantagens de propriedade de firmas de firmas domésticas.

\subsection{Investimentos outward}

Uma vez detectado um gap na Teoria IDP, os tópicos a seguir (que tratam de determinantes, motivações e vantagens competitivas) se propõem a listar fatores-chave que influenciam no comportamento dos OFDI e que não foram contemplados na Teoria IDP.

Os investimentos outward conferem inúmeras vantagens para todos os membros que participam da cadeia de investimento global, seja ele o país sede das multinacionais, seja o país hospedeiro, sejam as empresas multinacionais e domésticas envolvidas ou os setores envolvidos nas internacionalizações (Apergis, 2009; Baer\&Sirohi, 2013; Chen et al., 2012; Chow, 2012; Davies (2013); Globerman, 2012; Herzer, 2010; Kahanidra, 2013; Ketkar, 2014; Lee, 2010; Qiang, 2013; Quer et al., 2011; Radlo \& Sass, 2012; Rasiah et al., 2010).

Porém, com exceção da China, as economias emergentes ainda apresentam estoques pequenos de investimento outward em relação às economias desenvolvidas, apesar de uma participação cada vez maior no fluxo mundial de IDE (UNCTAD, 2013). Com o objetivo de compreender os determinantes de economias emergentes relacionados com o baixo estoque de investimentos outward, foi realizada revisão de estudos direcionados para análises em contextos de economias 
emergentes. O intuito foi compreender as peculiaridades desses países no que diz respeito aos investimentos diretos no exterior.

Goldstein e Pusterla (2010) argumentaram que oportunidades e desafios, tanto no país de origem como no país que hospeda investimentos outward, devem ser analisados quando firmas desejam investir no exterior. Com enfoque na análise de "países que recebem investimentos diretos", Baer e Sirohi (2013), Rasiah (2010) e Sauvant (2011) argumentaram que quando se tem a intenção de investir no exterior, as firmas precisam antes analisar alguns determinantes. Por exemplo, a riqueza dos países potenciais, reformas políticas de investimento e comércio, integração regional, liberalização financeira, nível de industrialização, possibilidades de construção de vantagens específicas para a firma, tamanho do mercado e infraestrutura (mão de obra, ferrovias, rodovias e portos).

Globerman (2012) defendeu que é preciso haver um grande potencial de demanda no país hospedeiro, assim como proximidade com fornecedores mundiais, baixo custo com transporte e estabilidade política e econômica. Annushkina e Colonel (2013), Khattab, Alrawad e Yatama (2011) e Quer et al. (2011) defenderam que as características que influenciam nas decisões de investimento no exterior são distância psíquica (em termos de cultura, práticas administrativas, clima, políticas econômicas, legislações) e risco político (expropriação, confisco, repúdio de contratos, restrições de propriedade e de pessoal, restrições de importações e exportações, terrorismo, revoluções e guerras e sansões econômicas). Dib et al. (2010) argumentaram que algumas firmas já nascem globalizadas e alguns fatores ambientais são determinantes para os empreendedores na decisão de um processo de internacionalização, tais como o tamanho do mercado e as economias intensivas em conhecimento.

Davies (2013), Rasiah (2010), Yan, Hong e Ren (2010) discutiram que o apoio governamental no país hospedeiro é crucial para o aumento do volume de investimentos diretos no exterior. Davies (2013) inclusive discutiu o exemplo do apoio do governo chinês à internacionalização das 
firmas domésticas. Segundo o autor, com a criação do plano de governo denominado Go Global, o governo chinês criou sólidas instituições financeiras para tratar exclusivamente de operações internacionais de firmas chinesas, como é o caso do Eximbank e do Banco de Desenvolvimento da China.

Mudando o enfoque da análise para o "país de sede das multinacionais investidoras", e não mais para o país receptor de investimentos, Chow (2012) argumentou que diferenças significativas de fatores econômicos e políticos entre países de origem e países hospedeiros são cruciais na decisão do investimento externo. $\mathrm{O}$ autor acrescenta que a disponibilidade de terras para uso industrial, os custos de aquisição e aluguel de maquinários, a taxa de juros local, a taxa de câmbio local, assim como regulações ambientais são fatores chaves que podem "empurrar" investimentos de firmas locais para o exterior. Já Radlo e Sass (2012) acrescentaram que um dos fatores mais importantes do país de origem é a situação financeira da firma e sua posição de mercado. Segundo os autores, se a competição na indústria local estivesse acirrada e o mercado doméstico saturado, firmas domésticas estariam inclinadas a investir seus lucros no mercado externo.

Complementando a argumentação de Barreto e Rocha (2003), Radlo e Sass (2012) explicaram que a limitação de crescimento no mercado doméstico faz com que as empresas busquem no exterior uma forma de consolidar uma estrutura de atendimento mais adequada a seus clientes, que vêm apresentando características cada vez mais globalizadas. Barreto e Rocha (2003) acrescentaram, ainda, que a internacionalização podia gerar inúmeras oportunidades de negócios para as firmas locais e ajudar na aquisição de poder de mercado a nível global.

Após fazer a revisão dos determinantes que influenciam decisões de IDE outward, percebe-se que a Teoria IDP, que é muito rica na explicação do comportamento dos IDE, poderia contribuir ainda mais para a área de negócios internacionais, caso considerasse determinantes macro e microambientais, conforme mostrado a seguir: 
- A Teoria IDP limita-se a tentar explicar o comportamento dos IDEs com base em três variáveis: PIB per capita, vantagens de propriedade e vantagens de localização. Então, considerar determinantes macro, meso e microambientais tanto do país sede das MNEs como do país hospedeiro é importante para a generalização da teoria quanto para uma melhor compreensão da dinâmica dos IDEs.

- Determinantes macro, meso e microambientais do paíssede (saturação de mercados, alta concorrência, incentivos governamentais...) "empurram" investimentos de firmas domésticas para o nível global.

- Determinantes macro, meso e microambientais do país hospedeiro (grandes mercados, recursos naturais disponíveis, mão de obra barata, proximidade cultural) "puxam" investimentos de firmas domésticas para o nível global.

\subsection{Motivações das estratégias de investimentos outward}

A motivação das estratégias de IDEs outward seriam as mesmas em economias desenvolvidas e em economias emergentes? De acordo com autores seminais, como Dunning (1980; 1988), as motivações por trás das estratégias de investimentos do tipo outward eram quatro: (1) buscar mercados, (2) buscar recursos, (3) buscar eficiência, e (4) buscar ativos estratégicos. Holtbrugge e Kreppel (2012) complementaram que tais motivações se enquadram em três grandes grupos: país (macro), indústria (meso) e firma (micro).

Arita (2013), assim como Radlo e Sass (2012), deram enfoque na discussão sobre a busca de mercados explicando que devido a similaridades na estrutura organizacional e no ambiente empresarial é provável que haja um nível mais alto de familiaridade entre mercados em desenvolvimento, do que entre um mercado desenvolvido e outro em desenvolvimento. Além disso, firmas que eram familiares à cultura de países estrangeiros tinham vantagens na aquisição da fidelidade do consumidor estrangeiro. Esses fatores, segundo os autores, ajudavam 
a explicar a preferência das multinacionais de economias emergentes por mercados também em desenvolvimento, podendo-se considerar que as imperfeições desses mercados propiciavam oportunidades de investimentos locais.

Segundo Globerman (2012), um dos principais objetivos da busca por recursos era o acesso a recursos naturais de alta qualidade ou com preços abaixo da média do mercado internacional, que eram escassos no país de origem das firmas investidoras. Globerman (2012) argumentou que a firma pode buscar recursos estratégicos (ativos estratégicos), como ativos relacionados a conhecimento (tecnologia, mão de obra qualificada), estabelecendo subsidiárias em países que dispõem dessas vantagens de localização. Por fim, o autor defendeu que as firmas podem direcionar suas estratégias de internacionalização motivadas pela busca de eficiência, que resultaria no aumento de sua competitividade internacional. Segundo o autor, os principais drives na busca pela eficiência eram as reduções nos custos transacionais, acesso a mão de obra barata e acesso a pacote de subsídios conferidos pelo governo locai de países hospedeiros.

Yaprak e Karademir (2010) argumentaram que a busca por novos mercados (com base no tamanho do mercado e no poder de compra da população) era uma forma de "driblar" a concorrência acirrada do mercado doméstico ou as barreiras rígidas de mercado ocasionadas por legislações ineficientes ou infraestrutura precária. Segundo os autores, tais características, típicas de economias emergentes, serviriam de alternativa (trade off) para as firmas locais, no sentido de que elas poderiam buscar no exterior meios de alavancar os lucros estáveis ou decrescentes do mercado doméstico, conferindo às firmas vantagens específicas de propriedade.

Arita (2013) complementou que, quando comparadas às firmas multinacionais de economias desenvolvidas, as multinacionais de economias emergentes tendiam a ter portes menores, níveis menores de tecnologia empregada na produção, menor expertise da equipe de gestão. Yaprak e Karademir (2010) complementaram que a firma 
também poderia buscar recursos de países hospedeiros, internalizando e transformando esses recursos em vantagens específicas de propriedade essenciais para a competição em mercados intensivos em tecnologia e no próprio mercado doméstico. De acordo com Davis (2013) e a UNCTAD (2013), a busca por recursos estratégicos era fundamental para firmas de economias emergentes, uma vez que elas poderiam adquirir escala, ter acesso a tecnologias e qualificações, conferindo-lhes vantagens competitivas em longo prazo.

A análise das motivações por trás dos investimentos outward de firmas de economias emergentes permitiu se pensar em três proposições:

- Existem quatro motivações relacionadas com investimentos outward: (1) buscar mercados, (2) buscar recursos, (3) buscar eficiência e (4) buscar ativos estratégicos.

- Tais motivações por trás dos investimentos outward se enquadram em três grandes grupos: país, indústria e firma.

- As motivações por trás dos investimentos outward de firmas de economias emergentes são diferentes das motivações de firmas em economias desenvolvidas.

\subsection{Vantagens competitivas em investimentos outward}

As motivações por trás dos investimentos outward de firmas de economias emergentes são diferentes das motivações de firmas em economias desenvolvidas. Isto pode se dar pela diferença no estoque de vantagens competitivas entre firmas de ambos os países. Goldstein e Pusterla (2010) argumentaram que através dos investimentos do tipo outward as firmas obtinham recursos estratégicos que lhe conferiam vantagens competitivas. Segundo Kaya e Erden (2008), as vantagens específicas (vantagens de propriedade, segundo Dunning, 1988) da firma eram divididas em quatro categorias: (1) vantagens relacionadas à operação (isto é, imagem da marca, experiência internacional, know how tecnológico), (2) vantagens relacionadas ao produto (qualidade e diferenciação), (3) vantagens relacionadas ao mercado (compromisso das firmas com atividades internacionais, habilidade de adaptação a 
mercados diferenciados, acesso à rede de networks e (4) vantagens de gestão (política de preços competitivos, velocidade de resposta à demanda dos consumidores, habilidade de aplicar práticas de gestão efetivas, experiência internacional dos tomadores de decisões).

De acordo com Johanson e Mattsson (1988), tais vantagens variavam de acordo com a idade e o porte da empresa e influenciavam em estratégias de entrada em mercados estrangeiros (joint ventures, aquisição, franquias) - estratégias essas reguladas por decisões que envolviam as variáveis "controle" versus "incerteza" (Johanson \& Vahlne, 1990). Portanto, para internacionalizar de forma sustentável, era preciso, em um primeiro momento, que a firma já tivesse adquirido vantagens competitivas em seu mercado doméstico, seja por uma network local, seja por um apoio governamental, ou por uma concorrência ou parceria com firmas multinacionais estrangeiras que resultassem em transferência tecnológica, modernização de máquinas, equipamentos e sistemas, capacitação da mão de obra local, entre outros (Johanson \& Mattsson, 1988; Narula \& Dunning, 1996; Yaprak \& Karademir, 2009; Davies, 2013).

A análise das vantagens competitivas que viabilizam os investimentos outward de firmas de economias emergentes permite listar mais três proposições:

- As vantagens competitivas podem ser classificadas em quatro categorias: vantagens relacionadas à operação, ao produto, ao mercado e à gestão.

- As vantagens competitivas de firmas de economias emergentes são limitadas quando comparadas às vantagens de firmas de economias desenvolvidas. Tal diferença influencia diretamente nas motivações das estratégias de IDEs outward.

- Firmas de economias emergentes precisam adquirir vantagens competitivas no mercado doméstico, em um primeiro momento, para que possam viabilizar estratégias de investimentos outward no médio ou longo prazo, seguindo sempre uma lógica incremental. 


\section{Proposta de um arcabouço teórico}

Após a análise dos artigos selecionados e o confronto da contribuição desses artigos com as premissas da Teoria IDP, chegouse a treze proposições relacionadas aos investimentos outward em economias emergentes. Agora será mostrado como as proposições se relacionam e ajudam a explicar o comportamento dos investimentos outward no âmbito das economias emergentes. Na Figura 5, observamse, de forma agrupada, as proposições resultantes desta pesquisa em cinco blocos, onde cada bloco responde as perguntas de pesquisas inicialmente propostas na introdução.

Figura 5 - Proposições da pesquisa

\begin{tabular}{|l|l|}
\hline Perguntas de Pesquisa & Proposições \\
\hline $\begin{array}{l}\text { 1: Qual o comportamento dos } \\
\text { investimentos inward e outward } \\
\text { nas economias emergentes? }\end{array}$ & $\begin{array}{l}\text { P1: O NOI é diferente em economias desenvolvidas e em } \\
\text { desenvolvimento. Enquanto em economias desenvolvidas } \\
\text { o NOI é positivo (estoque de IDE outward > estoque de } \\
\text { IDE inward), nos países em desenvolvimento o NOI } \\
\text { é negativo (estoque de IDE outward < estoque de IDE } \\
\text { inward). }\end{array}$ \\
\hline \multirow{5}{*}{$\begin{array}{l}\text { P2a: A Teoria IDP complementa P1 (o estoque de IDE } \\
\text { inward é maior do que o estoque de IDE outward em } \\
\text { países em desenvolvimento, caracterizando um NOI } \\
\text { negativo). Segundo a Teoria IDP, ao longo do tempo, o } \\
\text { investimentos inward e outward } \\
\text { nas economias emergentes? }\end{array}$} & $\begin{array}{l}\text { NOI passará de negativo a positivo, caracterizando uma } \\
\text { evolução dos investimentos outwards em países em } \\
\text { desenvolvimento. } \\
\text { P2b: Segundo a Teoria IDP, a evolução do NOI de } \\
\text { negativo a positivo se dá em cinco etapas. Em cada } \\
\text { uma das cinco etapas, a evolução do NOI tem relação } \\
\text { direta com desenvolvimento econômico (PIB per capita), } \\
\text { vantagens de localização e vantagens de propriedade. } \\
\text { P2c: A explicação da evolução do NOI, proposta pela } \\
\text { Teoria IDP, é limitada, uma vez que deixa de considerar } \\
\text { a influência de outras variáveis macro, meso e e } \\
\text { microambientais no comportamento dos IDEs. }\end{array}$ \\
\hline
\end{tabular}




\begin{tabular}{|c|c|}
\hline $\begin{array}{l}\text { 3: Quais os determinantes dos } \\
\text { investimentos outward nas } \\
\text { economias emergentes? }\end{array}$ & $\begin{array}{l}\text { P3a: A Teoria IDP limita-se a tentar explicar o } \\
\text { comportamento dos IDEs com base em três variáveis: } \\
\text { PIB per capita, vantagens de propriedade e vantagens } \\
\text { de localização. Então, considerar determinantes } \\
\text { macro, meso e microambientais tanto do país sede } \\
\text { das MNEs como do país hospedeiro é importante para } \\
\text { a generalização da teoria quanto para uma melhor } \\
\text { compreensão da dinâmica dos IDEs. } \\
\text { P3b: Determinantes macro, meso e microambientais do } \\
\text { país sede (saturação de mercados, alta concorrência, } \\
\text { incentivos governamentais...) "empurram" investimentos } \\
\text { de firmas domésticas para o nível global. } \\
\text { P3c: Determinantes macro, meso e microambientais do } \\
\text { país hospedeiro (grandes mercados, recursos naturais } \\
\text { disponíveis, mão de obra barata, proximidade cultural) } \\
\text { "puxam" investimentos de firmas domésticas para o nível } \\
\text { global. }\end{array}$ \\
\hline $\begin{array}{l}\text { 4: Quais as motivações dos } \\
\text { investimentos outward nas } \\
\text { economias emergentes? }\end{array}$ & $\begin{array}{l}\text { P4a: Existem quatro motivações relacionadas } \\
\text { com investimentos outward: (1) buscar mercados, (2) } \\
\text { buscar recursos, (3) buscar eficiência e (4) buscar ativos } \\
\text { estratégicos. } \\
\text { P4b: Tais motivações por trás dos investimentos outward } \\
\text { se enquadram em três grandes grupos: país, indústria e } \\
\text { firma. } \\
\text { P4c: As motivações por trás dos investimentos outward } \\
\text { de firmas de Economias emergentes são diferentes das } \\
\text { motivações de firmas em economias desenvolvidas. }\end{array}$ \\
\hline $\begin{array}{l}\text { 5: Quais as vantagens } \\
\text { competitivas que as firmas } \\
\text { de economias emergentes } \\
\text { precisam adquirir para que } \\
\text { possam executar, de forma } \\
\text { sustentável, estratégias de } \\
\text { investimentos outward? }\end{array}$ & $\begin{array}{l}\text { P5a: As vantagens competitivas podem ser classificadas } \\
\text { em quatro categorias: vantagens relacionadas à } \\
\text { operação, ao produto, ao mercado e à gestão. } \\
\text { P5b: As vantagens competitivas de firmas de economias } \\
\text { emergentes são limitadas quando comparadas às } \\
\text { vantagens de firmas de economias desenvolvidas. Tal } \\
\text { diferença influencia diretamente nas motivações das } \\
\text { estratégias de IDEs outward. } \\
\text { P5c: Firmas de economias emergentes precisam } \\
\text { adquirir vantagens competitivas no mercado doméstico, } \\
\text { em um primeiro momento, para que possam viabilizar } \\
\text { estratégias de investimentos outward no médio ou longo } \\
\text { prazo, seguindo sempre uma lógica incremental. }\end{array}$ \\
\hline
\end{tabular}

Fonte: Autores.

Em suma, a Teoria IDP, embora tenha contribuído significativamente para a compreensão do comportamento dos IDEs, deixa de considerar fatores macro, meso e microambientais em seu modelo, impactando negativamente na sua validade interna e externa. Há a proposição de 
um modelo, em cinco etapas, mostrando a dinâmica entre IDEs inward e outward, sob o efeito de variáveis de desenvolvimento (PIB per capita), variáveis de propriedade e variáveis de localização. No entanto, Narula e Dunning (1996; 2010) não explicam "como" se dá tal comportamento. Esse "gap" na teoria motivou esta pesquisa, cujos principais resultados foram apresentados na forma das proposições citadas acima e serão agora integrados na forma de arcabouço teórico (Figura 6), considerando de forma holística a relação entre IDE inward e outward em economias emergentes, como mostrado nos três pontos listados a seguir:

1. IDE inward maior que IDE outward: corroborando com os dados estatísticos da UNCTAD e com a Teoria IDP, em um primeiro momento, as economias emergentes apresentam imperfeições de mercado que impactam negativamente na competitividade global de suas firmas. Segundo Arita (2013) e Yaprak e Karademir (2010), tais imperfeições, caracterizadas por escassez de capital para investimentos, de mão de obra qualificada, de know how tecnológico, entre outros fatores, funcionam como uma força que "puxa" (Figura 6) IDEs inward de firmas estrangeiras, que buscam não só explorar tais imperfeições de mercados, dada suas vantagens competitivas em relação às firmas domésticas, como também explorar isenções e subsídios oferecidos pelo governo local, que veem no IDE inward uma fonte de transferência de conhecimento e fomento do desenvolvimento do parque industrial local.

2. Transferência de conhecimento: um segundo ponto a destacar no arcabouço teórico proposto neste ensaio é a explicação de como se dá a transferência de conhecimento ocasionada por volumes crescentes de IDEs inward em economias em desenvolvimento (Figura 6). Essa explicação não é tratada na Teoria IDP, e poucos pesquisadores detalham tal fluxo de conhecimento, o que representa um oportunidade para pesquisas futuras na área de IDEs. Porém, baseandose nas premissas da Teoria IDP, no início do recebimento dos IDE inward, apresenta vantagens de localização "atrativas" 
(isenções tarifárias, de impostos, subsídios de governos, acesso a recursos naturais, mão de obra barata e assim por diante) e suas firmas apresentam vantagens de propriedade pouco significativas. No entanto, ao longo do tempo, o contato contínuo entre firmas estrangeiras e firmas locais promove o fluxo de conhecimento mútuo, aumentando as vantagens de propriedade das firmas domésticas (melhor capacitadas) e diminuindo as vantagens de localização, em função do aumento da competitividade interna e consequente saturação do mercado. Cabe ressaltar a importância de se explicar mais detalhadamente como se dá tal transferência de conhecimento entre firmas estrangeiras e locais e o impacto da transferência na dinâmica entre IDEs inward e outward.

Figura 6 - Representação gráfica da transferência de conhecimento resultante da incidência dos IDEs inward sobre firmas locais aplicada aos cinco estágios da Teoria do Caminho do Desenvolvimento dos investimentos (IDP Theory)

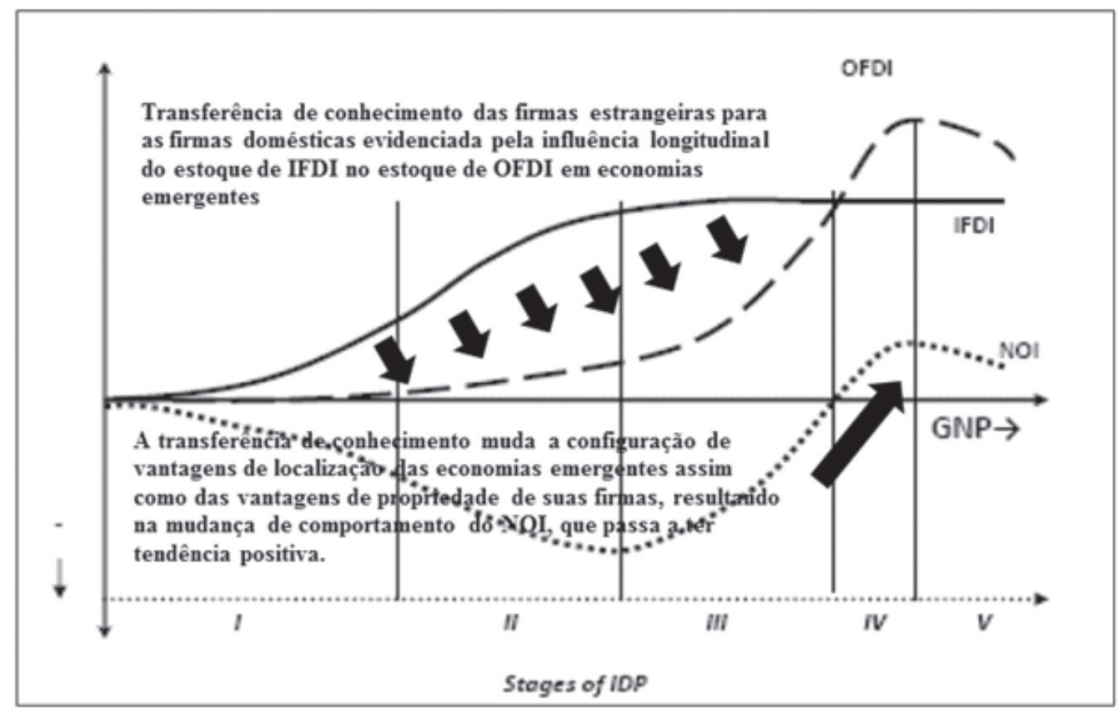

Fonte: Adaptada de Narula e Dunning (1996). 
3. IDE outward maior que IDE inward: com parques industriais mais desenvolvidos, firmas com networks mais consolidados e mão de obra melhor qualificada, o contexto dos s passa de muito atrativo para pouco atrativo em relação aos IDEs inward. Como discutido anteriormente, as vantagens competitivas das firmas domésticas aumentam, consequência da constante interação com multinacionais. Dessa forma, o ambiente se torna mais agressivo e as respectivas margens de lucro decrescem. Esse ponto sinaliza, então, a necessidade de buscar novos mercados que maximizem a rentabilidade das firmas domésticas. E a internacionalização via IDE outward, mesmo tardia (quando comparada com firmas de economias desenvolvidas), passa a ser relevante não só pela ótica da rentabilidade, mas também pela consolidação global das firmas. Nesse momento, os IDEs são "empurrados" (Figura 6) para fora dos s, pelo motivos assinalados anteriormente. Mais ainda, percebe-se uma postura mais protecionista nos governos nesta etapa, uma vez que o interesse não é mais a atração de IDEs inward para capacitação local, mas o fomento da expansão internacional das firmas domésticas, que resultarão em um novo aumento da competitividade do país, das firmas e dos setores locais, agora com ênfase global.

A Figura 7 representa graficamente o comportamento dos IDEs em economias emergentes considerando um número mais amplo de determinantes, quando comparado com o modelo proposto por Narula e Dunning (1996). 
Figura 7 - Arcabouço dos determinantes que influenciam no comportamento dos investimentos outward de firmas de economias emergentes.

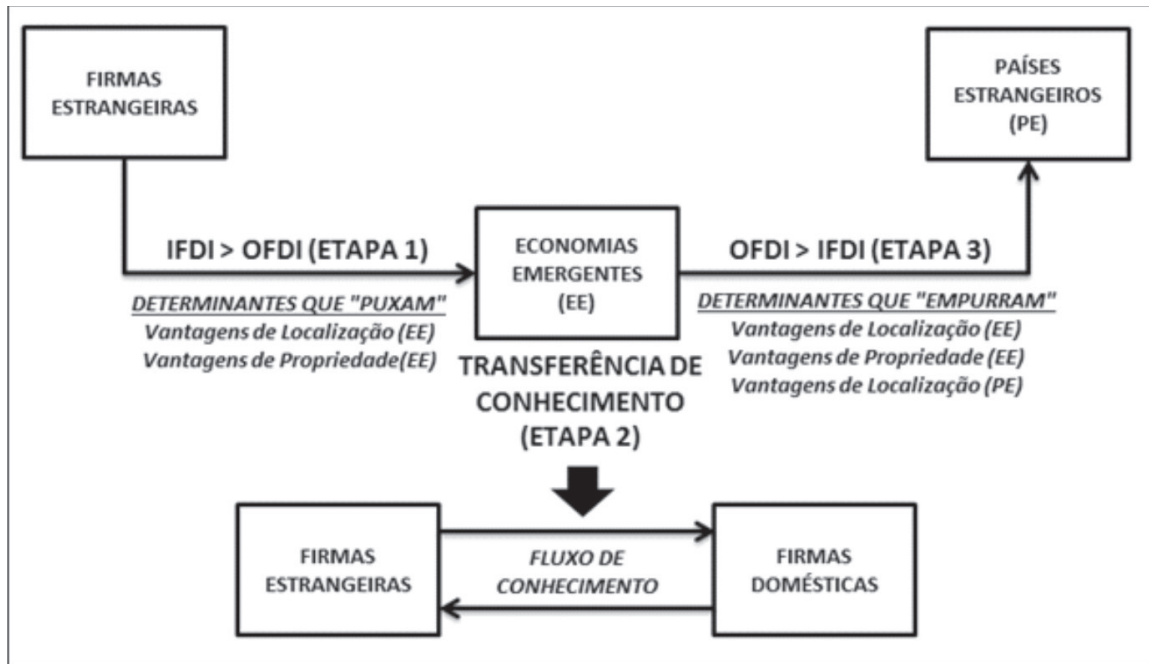

Fonte: Narula e Dunning (1996).

Primeiro, os IDEs são influenciados por fatores que os "puxam" para economias emergentes, dada as oportunidades locais. Em um segundo momento, o contato entre firmas estrangeiras e firmas de mercados emergentes viabiliza a transferência de conhecimento entre ambas as firmas (transferência de conhecimento não listada como determinante pela Teoria IDP para o desenvolvimento econômico local). Em um terceiro momento, já com o desenvolvimento de vantagens competitivas das firmas domésticas, os IDEs passam a orientar-se por fatores que os "empurram" para mercados estrangeiros.

\section{Conclusão}

Muitos são os benefícios que os investimentos outward geram para os países e para as firmas investidoras (Apergis, 2009; Baer \& Sirohi, 2013; Chen et al. 2012; Chow, 2012; Davies, 2013; Globerman, 
2012; Herzer, 2010; Lee, 2010; Kahanidra, 2013; Ketkar, 2014; Quer et al., 2011; Qiang, 2013; Radlo \& Sass, 2012; Rasiah et al., 2010).

Porém, como apresentado pelo relatório UNCTAD (2013), a participação das economias emergentes no estoque de investimentos outward mundial ainda é pequena. Buscou-se, então, analisar os determinantes relacionados aos investimentos outward em economias emergentes e suas motivações para viabilizar tais investimentos.

Esta pesquisa possibilitou compreender o cenário dos IDE tanto em economias desenvolvidas como emergentes, uma vez que se constatou que nas economias desenvolvidas o estoque de IDE outward é maior do que o estoque de IDE inward. Por sua vez, observou-se um comportamento oposto nas economias emergentes que apresentaram estoque de IDE inward maior do que o estoque de IDE outward.

A escolha da Teoria IDP como base deste ensaio possibilitou uma compreensão mais detalhada do comportamento dos IDEs nas economias emergentes, conforme descrito pelo relatório da UNCTAD. De acordo com a teoria proposta por Narula e Dunning (1996), economias emergentes apresentam um estoque maior de IDE inward do que IDE outward. No entanto, segundo os autores, esse quadro pode mudar ao longo do tempo, e o estoque de IDE outward pode superar o de IDE inward, conforme o desenvolvimento do país. A teoria, inclusive, sugere cinco etapas para que aconteça essa mudança de quadro, sendo tal mudança moderada pelo desenvolvimento local (mensurado pelo PIB per capita) e por variações nas vantagens de propriedade das firmas domésticas e de localização do país receptor.

Porém, detectou-se um gap na Teoria IDP, uma vez que ela não considera a influência de diversos outros determinantes diretamente relacionados com o comportamento dos IDEs outward. A fim de explorar esse gap, e tendo como suporte a revisão de pesquisas empíricas sobre IDEs, mapeou-se um grupo de determinantes que complementam as explanações de Narula e Dunning sobre o comportamento dos IDEs outward em economias emergentes. Tais determinantes podem ser divididos em dois grupos - determinantes que "puxam" e determinantes 
que "empurram" IDEs. Defende-se, ainda, que tais determinantes devem ser considerados sob a ótica macro (nível econômico), meso (nível setor) e micro (nível firma) para que o fenômeno dos investimentos outward possa ser visto de forma holística e, portanto, melhor compreendido e analisado.

Como contribuição principal desta pesquisa, foi proposto um arcabouço teórico que compila os determinantes não abordados pela Teoria IDP. Sugere-se, no entanto, que tal arcabouço seja testado empiricamente em pesquisas para validação de suas proposições. Uma vez validado, tal arcabouço poderá ser utilizado para orientação de estratégias de internacionalização de firmas com sede em economias emergentes, assim como para direcionamento de políticas governamentais.

Finalmente, é importante reconhecer as limitações de pesquisa. A apresentação do arcabouço teórico, que complementa a Teoria IDP de Narula e Dunning (1996), é uma simplificação do fenômeno dos investimentos outward em economias emergentes. Como toda simplificação, muitos fatores deixaram de ser considerados, principalmente quando se trata de um tema tão complexo como negócios internacionais, que envolve também relações diplomáticas entre países, questões tributárias e fiscais, dentre outros. Por outro lado, modelos e arcabouços devem mostrar-se úteis a despeito das omissões e simplificações necessárias para que se tornem operacionais. Se bem sucedido, este será o caso do arcabouço ora proposto. A partir dele, espera-se que novos e melhores modelos possam ser propostos para lidar com as questões ligadas aos investimentos outward.

\section{Referências}

Annushkina, O., \& Colonel, R. (2013). Foreign market selection by Russian MNEs - beyond a binary approach? Critical perspectives on international business, Emerald Group Publishing Limited, (9) 1/2. 58-87. 
Apergis, N. (2009). Foreign Direct Investments inward and outward; evidences from panel data, developed and developing economies, and open and close economies. The American Economist, University of Piraeus, Department of Banking and Financial Management, (54) 2, 20-28.

Arbix, G. (2010). Structural change and the emergence of the Brazilian MNEs. International Journal of Emerging Markets, Emerald Group Publishing Limited, (5) 3/4, 266-288.

Arita, S. (2013). Do emerging multinational enterprises possess SouthSouth FDI advantages? International Journal of Emerging Markets, Emerald Group Publishing Limited, (8)4, 329-353.

Baer, W., \& Sirohi, R. (2013). The Role of Foreign Direct Investments in the Development of Brazil and India: A Comparative Analysis. KYKLOS, Blackwell Publishing Ltd., 9600 Garsington Road, Oxford OX4 2DQ, UK and 350 Main Street, Malden, MA 02148, USA, (66) 1, 46-62.

Chen, Y., HSU, W.-C., \& WANG, C. (2012). Effects of outward FDI on home-country export competitiveness. Journal of Chinese Economic and Foreign Trade Studies, Emerald Group Publishing Limited, (5) 1, 56-73.

Chow, P. (2012). The effect of outward foreign direct investment on home country's export: A case study on Taiwan, 1989-2006. The Journal of International Trade \& Economic Development, Taylor \& Francis Group, (21) 5, 725-754.

Davies, K. (2013). China Investment Policy. OECD Working Papers on International Investment, OECD Publishing, pp. 1-77.

Dib, L., ROCHA, A., \& SILVA. (2010). The internationalization process of Brazilian software firms and the born global phenomenon: Examining firm, network, and entrepreneur variables. Journal of International Entrepreuneurship, McGill University, Canada, V.8, pp. 233-253. 
Dunning. (1980). Toward to an Ecletic Theory of International Production: some empirical tests. Journal of International Business Studies, London, United Kingdom, v. 11, (1), p. 9-31.

Dunning, J. (1988). The ecletic paradigm of international production: a restatement and some possible extensions. Journal of International Business Studies, Palgrave Macmillan Journals, pp. 1-31.

Dunning, J. (1991). The Nature of Transnational Firm. Edited by Christos N. Pitelis and Roger Sugden, Routledge London and New York, pp. 117-135.

Globerman, S. (2012). Investing abroad and investing at home: complements or substitutes? Multinational Business Review, Emerald Group Publishing Limited, (20) 3, 217-230.

Goldstein, A., \& Pusterla, F. (2010). Emerging economies' multinationals: General features and specificities of the Brazilian and Chinese cases. International Journal of Emerging Markets, Emerald Group Publishing Limited, (5), 3/4, 289-306.

Goldstein, A., Gammeltoft, P., \& Pradhan, J. (2010). Emerging multinationals: home and host country determinants and outcomes. International Journal of Emerging Markets, Emerald Group Publishing Limited, (5) 3/4, 254-265.

Herzer, D. (2010). Outward FDI and economic growth. Journal of Economic Studies, Emerald Group Publishing Limited, (37) 5, 476494.

Holtbrugge, D., \& KreppeL, H. (2012). Determinants of outward foreign direct investment from BRIC countries: an explorative study. International Journal of Emerging Markets, Emerald Group Publishing Limited, (7) 1, 4-30.

Hsu. (2011). The effects of outward FDI on home-country productivity Do location of investiment and market orientation matter? Journal 
of Chinese Economic and Foreign Trade Studies, Emerald Group Publishing Limited, (4) 2, 99-116.

Johanson, \& Vahlne. (1977). The Internationalization Process os the Firm: a model of Knowledge development and increasing foreign market commitments. Journal of International Business Studies, Palgrave Macmillan Journals, pp. 23-32.

Johanson, \& Vahlne. (1990). The Machanism of Internalisation. International Market Review, (7) 4, 11-24.

Johanson, \& Vahlne. (2013). The Uppsala model on evolution The Uppsala model on evolution enterprise - from internalization to coordination of networks. International Marketing Review, Emerald Group Publishing Limited, (30) 3, 189-210.

Johanson, J., \& Mattsson. (1988). International Marketing and Internalization Process - A Network Approach. In: Internationalisation in Industrial Systems (Chapter 11), pp. 286-314.

Ju, K., Kim, K., \& Bae, S. (2012). Equity Ownership Determination in Foreign Direct Investments of Developing Economies: The Case of Korean Outward FDIs. Review of Pacific Basin Financial Markets and Policies, World Scientific Publishing Co. and Center for Pacific Basin Business, Economics and Finance Research, (15) 1, 1-32.

Kaya, H., \& Erden, D. (2008). Firm-specific capabilities and foreign direct investment activities of Turkish manufacturing firms: an empirical study. Journal of Management Development, Emerald Group Publishing Limited, (27) 7, 761-777.

Ketkar, S. (2014). The rules of global engagement for developing country firms. Competitiveness Review, Emerald Group Publishing Limited, (24) 2, 124-146.

Khanindra. (2013). A Perspective on India's Outward Foreign Direct Investment. Journal of International Economics, McGill University, Canada, (4) 1, 73-79. 
Khattab, A., Alrawad, \& Yatama. (2012). Executives' perception of political-legal business environment in international projects. International Journal of Commerce and Management, Emerald Group Publishing Limited, (22) 3, 168-181.

Lee, C. (2010). Outward Foreign Direct Investment and Economic Growth: Evidence from Japan. Global Economic Review, Yonsei University, Seoul, (39) 3, 317-326.

Liu, H., \& Lu, J. (2011). The home-employment effect of FDI from developing countries: in the case of China. Journal of Chinese Economic and Foreign Trade Studies, Emerald Group Publishing Limited, (4) 3, 173-182.

Narula, R., \& Dunning, J. (1996). Third World Multinationals Revisited: some emerging issues", in John $\mathrm{H}$. Dunning and Rajneesh Narula, eds., Foreign Direct Investment and Governments (London: Routledge), pp. 1-41.

Narula, R., \& Dunning, J. (2010). Multinational enterprises, development and globalisation: Some clarifications and a research agenda, Oxford Development Studies, (38) 3, 263-287.

Qiang, Y. (2013). How does OFDI affect trade development in developing countries? Journal of Chinese Economic and Foreign Trade Studies, Emerald Group Publishing Limited, (6) 2, 85-90.

Quer, D., Claver, E., \& Rienda, L. (2012). Political risk, cultural distance, and outward foreign direct investment: Empirical evidence from large Chinese firms. Asia Pacific Journal of Managment, New York, USA, Springer Science+Business Media, V.29, pp. 1089-1104.

Radlo, M.-J., \& Sass, M. (2012). Outward Foreign Direct Investments and Emerging Multinational Companies from Central and Eastern Europe. Eastern European Economics, Arizona State University, USA, (50) 2, 5-21. 
Rasiah, R., Gammeltoft, P., \& Jiang, Y. (2010). Home government policies for outward FDI from emerging economies: lessons from Asia. International Journal of Emerging Markets, Emerald Group Publishing Limited, (5) 3/4, 333-357.

Sauvant, K. (2011). China: Inward and Outward Foreign Direct Investment. Transnational Corporations Review, (3) 1, 1-5.

Unctad. (2013). Global Values Chains: investments and trade for development. World Investment Report, United Nations, pp.1-264.

Yan, D., Hong, J., \& Ren, B. (2010). Determinants of outward foreign direct investment by Chinese enterprises: An empirical study from institutional perspective. Nankai Business Review International, Emerald Group Publishing Limited, (1) 3, 237-253.

Yaprak, A., \& Karademir, B. (2010). The internationalization of emerging market business groups: an integrated literature review. International Marketing Review, Emerald Group Publishing Limited, (27) 2, 245262.

Artigo recebido em: 11/09/2015

Aprovado em: 16/12/2015 